\title{
Exploring intercultural competence through an intercultural extracurricular activity in Taiwan
}

\author{
Kai Li LIU \\ Soochow University, Taiwan \\ liukl@scu.edu.tw
}

\begin{abstract}
This study used interviews to explore how 10 Taiwanese college students' intercultural competence was developed after participating in an intercultural extracurricular activity designed with a purpose to facilitate foreign students' study in Taiwan and to promote meaningful home-foreign student contacts. In-depth information and narratives from the interviews were collected as evidence of intercultural competence development. The results showed all the interviewees appreciated the experience and felt it to have been of value to them in terms of building international friendships, heightening their intercultural awareness and the benefits of intercultural competence, and having more appreciation and better understanding of Taiwanese culture. Students also realized that a lack of understanding of Taiwanese culture could exacerbate communication difficulties. Students thus became aware of the importance of describing Taiwanese cultural practices in English and realized that more language practice was necessary for smoother communication. Suggestions for both extracurricular activities and language programs improvement in the future were also provided in the conclusion.
\end{abstract}

Keywords

intercultural competence

\section{Introduction}

The topic of intercultural learning has received much interest due to the rise of globalization. When English is used as a tool of communication and interaction with people worldwide, people have more opportunities to experience intercultural learning through using English as an international language to communicate with non-native speakers. This indicates the importance of teaching the intercultural dimension in a foreign language classroom so that students will be prepared to function in the international contexts.

Traditionally, many institutions have facilitated the development of intercultural competence through study abroad programs (Dolby, 2008; Rundstrom, 2005) and indeed, study abroad has been linked to many positive intercultural learning outcomes (Vande Berg, Connor-Linton, \&Paige, 2009; Weber, 2005). However, studying abroad is not accessible or affordable opportunity to all students. For the majority of university students, foreign language classes are the most important forms of access to the development of intercultural competence. However, some studies (Sung \& Chen, 2007; Sung \& Chen, 2009) have shown that language teachers often are limited in terms of their own knowledge or in the teaching support they receive which in turn affects the promotion of intercultural learning. Moreover, authentic environments for language use are often limited or completely lacking, posing a further challenge to EFL teachers and learners. Theorists also argue that experiential learning of a culture is more effective than learning that is confined within a classroom (Byran \& Feng, 2004). To address such challenges, student diversity on campus is a valuable resource for the development students' intercultural competence.

In recent years, the universities in Taiwan have been making strategic efforts to address their internationalization goals. One strategy is to bring in more foreign students, making the university more 
international in terms of the languages, cultures and viewpoints reflected within the student body. An internationalized campus can thus become an culturally diverse context in which to provide opportunities for the experience of intercultural learning, including language learning as well as other aspects, and to develop intercultural communicative competence without the necessity of going abroad.

Some studies suggest that well-designed tasks and activities as well as appropriate guidance and support are important elements for promoting meaningful intercultural learning (Miyamoto, 2012; Liu, 2012). Leask (2009) also concludes that the development of intercultural competence in students is one of the key outcomes sought in an internationalized curriculum. This in turn necessitates a campus environment and culture in which there are clear motivations for and rewards for interaction between international and local students inside and outside of the classroom.

Based on such an understanding of the diverse campus as a context for the real-life learning of language and culture, this study used a qualitative approach to explore the evidence of students' development of intercultural competence by investigating students' in-depth information and narratives after participation in one specific intercultural extracurricular activity.

\section{Literature review}

\section{Intercultural competence}

Intercultural competence has been recognized as an essential skill in the globalized world and studied by various scholars, who have attempted to define, model and assess it. Despite a number of differences among the models and conceptions, scholars generally concur that intercultural competence refers to the ability to interact effectively and appropriately with people from other cultures. Four dimensions-in particular: knowledge, attitude, skills and behaviors, can be seen in many definitions (Alred \& Byram, 2002; Bennett, 2008; Byram, 1997; Heyward, 2002; Hiller \& Wozniak, 2009; Lustin \&Koester, 2006). A person who has intercultural competence can develop relationships with people from different cultures, can resolve conflicts arising as a result of cultural differences and can improve his or her ability to do business with counterparts from different cultures (Huang, Rayner, \& Zhuang, 2003). Taylor (1994) defines intercultural competence as a transformative process through which the foreigner develops his or her adaptive capacity, altering his or her perspective to effectively understand and adapt to the demands of the host culture. Hence, learning to deal with different cultures effectively requires cultural awareness, communicative competence, as well as personality traits like empathy and flexibility, self-awareness along with a conceptual understanding others' values, norms and beliefs.

\section{The importance of intercultural competence}

Intercultural competence is the foundation of any international interaction. Globalization and worldwide contacts among companies, organizations and individuals requires of individuals the ability to communicate successfully. The rise of English as a global language implies a paradigm shift for English Language Teaching (ELT). Kachru $(1985,1991,1992,1998)$ categorizes the English as centerperiphery relationship in which the innermost circle comprises the countries in which English is the primary language such as the UK, Canada, USA, Australia and New Zealand. The next circle includes countries where English has official or historical importance such as India, the Philippines, and Singapore. Here English may serve as a useful lingua franca between ethnic and language groups. Higher education, the legislature and judiciary, national commerce, and so on, are all carried out more or less predominantly in English. The final, or expanding, circle refers to those countries where English has no official role in the state, but is nonetheless important for functions such as international business. In recent decades, the varieties of English used in the expanding circle have been reported to be the fastest growing sectors of world English. In the twenty-first century, non-native English speakers have come to significantly outnumber native speakers (Graddol, 1999; Gnutzmann, 2000). This indicates most verbal exchanges in which English is used as a foreign or second language involve nonnative users of English. For many English learners, the main purpose of learning English is to communicate with people the world, the majority of whom are non-native speakers (NNS). In 
traditional ELT, learners follow the NS norms and standards, trying to understand the rules and usages of the language set by native speakers (NS). In contrast, the global English paradigm holds that the importance of intelligibility and intercultural comprehension outweighs considerations of grammatical correctness and standardization.

\section{The development of intercultural competence}

Developing cultural dimension in language teaching has grown in the last two decades. What has to be taught and learned to develop intercultural competence are explicitly explained by Kramsch's quotation (Kramsch, 1998, p. 27): "The characteristic of a competent language user is not the ability to speak and write according to the rules of the academy and the social etiquette of one social group, but the adaptability to select those forms of accuracy and those forms of appropriateness that are called for in a given social context of use".

Byram (1997) adds: The desirable outcome is a learner with the ability to see and manage the relationships between themselves and their own cultural beliefs, behaviors and meanings, as expressed in a foreign language, and those of their interlocutors, expressed in the same language -or even a combination of languages - which may be the interlocutors' native language, or not.

Thus, the intercultural dimension in language teaching is developed in order to give learners intercultural as well as linguistic competence; to enable students to understand and accept people from other cultures as individuals with distinctive perspectives, values, and behaviors; and to help them to see such interaction as an enriching experience.

Some analyses of study abroad programs have found them to be an effective way to experience intercultural learning (Weber, 2005) and practice language. Language teachers also apply web-based technologies to promote intercultural learning (Chen, 2011; Ke, 2011; Lee, 2012). In contrast to these previous studies, this study explored the development students' intercultural competence as the result of participation in an extracurricular activity designed to promote intercultural learning outside the classroom and encourage English language use as a means of communication on an internationalized campus in Taiwan.

\section{The assessment of intercultural competence}

Research results indicate that intercultural competence can, indeed, be assessed (Deardorff, 2011; Fantini, 2009; Stuart, 2009). A great number of tools have been developed to measure intercultural competence. Most assessments of intercultural competence focus on results instead of process. Intercultural competence assessment must involve a multi-method, multi-perspective approach that is focused more on the process of intercultural competence than on an end result (Deardorff, 2012; Deardorff \& Edwards, 2012; Gordon \& Deardorff, 2013). Examples of how intercultural competence is currently being assessed include through embedded course assessment, self-report instruments, reflection papers, critical incident analysis, interviews, observations (by professors, internship supervisors, host families, group members, etc), simulations and longitudinal studies. While it is encouraging that more institutions are assessing intercultural competence outcomes, there is much work that needs to be done on improving intercultural competence assessment and as such, there are currently no examples of "best" practices.

\section{Method}

\section{Participants}

10 college students who voluntarily participated in an 18-week intercultural extracurricular activity, called SUSIS, on the campus of a university in Taiwan with a sizeable population of international students were interviewed for their intercultural learning experience. After an initial interview explaining the purpose and the process of this study to a total of 23 new SUSIS members at the beginning of the semester, 10 students, 7 female and 3 male, agreed to participate in this study with an understanding about confidentiality and signed a consent form. 


\section{Description of intercultural experience activity}

The intercultural experience activity that formed the basis of this study is called Soochow University students' international service (SUSIS). SUSIS is under the supervision of the international office of Soochow University, which mainly details international student affairs. Every semester the international office recruits local students as members of SUSIS, who are willing to offer service for 18 weeks, to welcome and assist foreign students. In addition to facilitating foreign students' study in Taiwan, SUSIS allows more frequent contacts with students from different cultures outside the classroom.

After recruiting the members of SUSIS, an orientation session at which the tasks the SUSIS members would be asked to complete during the 18 weeks were explained was provided. The SUSIS members were grouped according to the primary tasks assigned them; for example, group for picking up foreign students in the airport, group for help with check-in in the dorm, and group for help with housing rental if foreign students would like to live off campus. SUSIS members and foreign students collaborated on the organization of four major intercultural events intended to allow the students to get to know each another better. A buddy program was also established, providing participating students with greater opportunity to develop closer friendships. On the average, one SUSIS student took care of one to two foreign students. Pairs were formed as far as possible, based on students' fields of study. The scope, duration and frequency of interaction in this program provided SUSIS students with an intercultural experience that afforded possibilities of self-discovery standing in contrast to the second-or third-hand cultural knowledge or information passed on through teacher-directed classroom approaches.

\section{Data collection \\ Interviews}

An initial interview explained the purpose and the process of the research and allowed the researcher to develop rapport with the purposely selected participants. The 10 volunteers were contacted to set a time for a second interview at the end of the semester.

A flexible semi-structured interview, which allows new questions to be brought up in response of interviewee remarks, was conducted at the end of the semester. The choice of a semi-structured interview format was based on the idea that the researcher can gather detailed data, such as thoughts, feelings, intentions or beliefs (Denzin, 1989; Merriam, 1998), or what is " in and on someone else's mind" ( Patton, 1990, p. 278). Seidman (1998) also states that "at the root of in-depth interviewing is an interest in understanding the experience of other people and the meaning they make of that experience" (p. 3). A series of prearranged questions related directly to the research question were asked to elicit the responses from the 10 students who were divided into 4 groups due to scheduling considerations. Each small group, including 2-3 students, was interviewed for two 2 hours. Interviewees were allowed to respond either in Chinese or English. The contents of the interview were recorded, transcribed and translated into English with the interviewees' permission. Questions dealt with aspects of the participants' motivation to participate in SUSIS, their interaction engagement; their experience of cultural difference; accounts of their collaboration with people from different cultures; communication experiences developing linguistic and other skills; new knowledge and abilities applied and developed during the course of the program and as well as the challenges encountered. Informal, relaxed atmosphere maintained during the interviews encouraged the participants' open expression of ideas.

\section{Data analysis}

A thematic analysis (Braun \& Clarke, 2006; Owen, 1984) was performed to analyze the interviews. All the interviews were read thoroughly and repetitively to code important texts related to the research questions. Then the coded excerpts were categorized and given the initial themes which were reviewed continually and revised several times before the final themes were generated. 


\section{Results}

Five main themes were identified :(a) reasons for participation, (b) communication preferences (c) positive aspects perceived in development of intercultural communication competence,(d) challenges and (e) negative aspects of contact experience.

\section{Reasons for participation}

The ten interviewees were asked about the reasons for participation in SUSIS. All of them stated that the main purpose was to make friends with a foreign student and to learn more about other cultures. The most frequently stated reasons were: to build international friendship, to practice spoken English, to increase knowledge of other cultures, to help others, to learn team-work skills and to develop problem-solving skills. The following are representative quotes:

"I am interested in making friends from different cultures. I want to practice communication in English and hope to improve my English ability." (personal communication, March 4, 2015)

"This activity provides more opportunities to experience different cultures than other student clubs on campus. I think this is a good chance to increase knowledge and practice English communication and learn how to be a team player. I believe the experience of meeting people from different cultures cannot only broaden my horizons but also be helpful in my performance at workplace in the future." (personal communication, March 4, 2015)

"I want to learn more about the world by interacting with people from different cultures. Also I want to share and introduce the culture and the beauty of Taiwan with foreign students." (personal communication, March 4, 2015)

...to increase my confidence in using English and to learn social and problem-solving skills." (personal communication, March 4, 2015)

"I am going to be an exchange student next semester. I would like to take this opportunity to know why they want to study in Taiwan and help them adjust to the study in Taiwan if they have any difficulties. I believe this will also help me better prepare my study in a foreign country. I am glad that I can be a member of SUSIS and help foreign students. When I study abroad, I hope I can have a partner to help me too." (personal communication, March 4, 2015).

\section{Communication preferences}

When asked to describe the topics that they usually talk about in their meetings, all interviewees firmly expressed being able to talk about Taiwanese culture is the key for the successful interaction engagement. Foreign students are eager to know the local culture. Thus topics such as trips, food, restaurants and festivals are preferences in conversations. All the interviewees shared the same idea like the following quote:

"They often ask us where to eat delicious Taiwanese food and ask for advice for the trips. My partner and I visited Kinmen together during the spring break. He wanted to go there because of the famous alcohol there, Kao-Liang." (personal communication, March 4, 2015)

\section{Positive aspects of contact experience}

All interviewees felt SUSIS to have been of value to them and commented that although they were nervous at the beginning, they gained something from this intercultural learning experience. The most commonly mentioned gains were (1) friendship (2) English for real communication (3) appreciation of 
Taiwanese culture (4) better perception of intercultural communication and (5) Increasing intercultural awareness. Representative quotes are as follows:

"This is a very good chance to meet people from different cultures in my own school, especially for students like me who don't have the opportunity to study abroad. I remember at the welcome party, I was a little nervous and had no confidence. However, when a Japanese student tried to communicate with me by writing, I found out that in fact foreign students were not so unapproachable as I had thought. Despite my poor communication skills, I tried my best to converse with my partner. Through this experience I realized as long as we open our hearts, we can make more friends." (personal communication, March 4, 2015)

"My partner and I are doing a language exchange. I teach her Chinese and sometimes she helps me with my Japanese assignments. We meet every week and we go visit many places, such as night markets, Taizhong city and Tainan, my hometown together. I have a plan to visit her after she goes back to Japan this summer." (personal communication, March 4, 2015)

"It's very interesting to learn about other cultures through such direct contact. I have made a lot of international friends. My conversations with them show me how they look at Taiwan. As a Taiwanese student, it's my job to help them get to know Taiwan. As a result, I can see my own country from a different point of view and I have visited places I have never been to and eaten foods I have never tried before with foreign students. And I think Taiwan is really pretty." (personal communication, March 4, 2015)

" Here I can learn practical skills that I can't gain in the classrooms, such as problem-solving skills and real communication skills. Due to the language barrier, it's very important to ask for help or support from other SUSIS members who have better English proficiency to solve foreign students' problems. Sometimes it is difficult to understand their English. Students from different places, have different accents. My English is not so good either. Therefore, sometimes we use limited Chinese and English or sign language to communicate. That is fun too." (personal communication, March 4, 2015)

"Foreign students' lives and overseas experiences motivated me to see more of and learn more about the world. I want to travel and study abroad if possible. My partner told me he studied in China before coming to Taiwan. He recognizes the differences between the Chinese used in China and in Taiwan. Also the learning environment in Taiwan is much better and safer. At least not many people spit on the streets." (personal communication, March 4, 2015)

"This experience has increased my understanding of the importance of English as an international language for communication among people from different cultures. Many students speak English very fluently. I need to work harder to improve my proficiency." (personal communication, March 4, 2015)

Through the interviews, the development of the intercultural awareness, the foundation of intercultural competence, is identified as below.

"My impression of the westerners is that they are open and outgoing. But I found this is not to be so true. My partner is not enthusiastic as I had expected. She is shy and quiet and sometimes it took some time for us communicate well." (personal communication, March 4, 2015)

"In the classroom, my Japanese teacher taught us that it was a part of Japanese culture to show respect to others by not asking personal questions. However, my own experience showed me that it 
is not true for everyone. I also learned some real language use from my Japanese partner, which is different from what is taught in our textbooks." (personal communication, March 4, 2015)

"It's important to be more patient and be objective in an international relationship because things might not be going as well as I think they are. Sometimes I really don't know what subtle meanings my partner is trying to express during our interaction. " (personal communication, March 4, 2015)

"As long as we are open-minded and willing to try, we can make a lot of foreign friends and enjoy the interaction more. (personal communication, March 4, 2015)

\section{Challenges}

Despite these fruitful positive learning outcomes of their contact experiences, there were some problems identified. Two most commonly mentioned challenges faced by the subjects were (1) the language barrier and (2) difficulties in explaining their own culture. Typical remarks are as follows:

"At beginning, I couldn't express myself well. I felt upset. But I try to use a lot of gestures and sign language to communicate. And recently I think I have been making some progress in speaking." (personal communication, March 4, 2015)

"Students more proficient in English have more opportunities to talk to students from the West." (personal communication, March 4, 2015)

"Successful intercultural communication is not so easy. Lack of fluency in spoken English or poor listening comprehension can cause a lot of frustration, but I still believe this direct contact provides a good learning experience for intercultural communication." (personal communication, March 4, 2015)

"My partner is from Japan. His English is not so good either, so we sometimes have difficulties understanding each other. We always end up using smart phones to look up vocabulary in order to communicate." (personal communication, March 4, 2015)

"When we eat in the restaurant, it's very difficult to explain Taiwanese food in English to them. I don't know enough vocabulary to explain on the spot" (personal communication, March 4, 2015)

“ Because of my poor spoken English, my partners sometimes can't understand me at all, resulting in real embarrassment and frustration." (personal communication, March 4, 2015)

"During a trip to the museum in Yingge, my French partner asked me about the statues of gods and goddesses. I realized that I didn't know much about them myself. So, of course I was not able to explain it in English. I immediately used my cell phone to google it " (personal communication, March 4, 2015)

"I need to improve my listening comprehension. During the conversations, it was challenging for me to understand what they were saying or asking. I usually had to have people proficient in English help me out. This has really motivated me to study English harder in the future." (personal communication, March 4, 2015) 


\section{Negative aspects of contact experience}

Although the majority of the interviewees expressed a positive attitude regarding the benefits of this intercultural experience, not all interviewees felt they had achieved significant improvement in ICC. Three interviewees reported that their ICC had developed substantially. This was because the Japanese majors who had been matched with Japanese students were already somewhat familiar with Japanese culture or had already had experience interacting with Japanese students. Thus, they reported that they had not experienced much that was new to them. Another difficulty was related to scheduling. Most students reported difficulty in finding free time beyond the official scheduled activities to meet their buddies during the semester. This is shared by the following quote.

"I take classes on Main campus while my partner takes most classes on Downtown campus. It is impossible for us to meet each other often. If she doesn't need any help from me, we seldom contact each other." (personal communication, March 4, 2015).

\section{Discussion and conclusion}

Considering the need to maximize the opportunities of intercultural learning for the majority of university students, this study explored the effects of an intercultural engagement activity on the development of intercultural competence on an internationalized campus by interviews. The results showed the benefits of experiential learning, as well as indicating some of the challenges face and attitudinal changes undergone in the development of intercultural competence.

The interviewees' motivation to participate in SUSIS expressed their eagerness, openness, willingness and readiness for and interest in discovering, learning and experiencing other cultures through contacting with foreign students from various cultures. Such enthusiasm is just the attitude students are expected to have in the development of intercultural competence. Through SUSIS, all the interviewees appreciated the experience and felt it to have been of value to them in terms of building international friendships, heightening their intercultural awareness and the benefits of intercultural competence, and having more appreciation and better understanding of Taiwanese culture. The interviewees' attitudinal shifts became evident through this experience in several ways. Some were able to see the differences in language use between the real world and in the classroom. They realized that more efforts would be needed before they attained fluency. More than half of them gained new views and opportunities to explore their own culture. Some interviewees' stereotypes were broken down in this experience.

Aside from the benefits, students also encountered difficulties expressing themselves to foreign students in situations when the vocabulary is limited. In addition, most interviewees experienced communication problems when their foreign partners did not speak fluent English or spoke with unfamiliar accents. Students also realized that a lack of understanding of Taiwanese culture could exacerbate communication difficulties. Students thus became aware of the importance of describing Taiwanese cultural practices in English and realized that more language practice was necessary for smoother communication. They understand it needs more patience and more tolerance in a foreign friendship.

Despite the challenges and negative views reported therein, the interview results have shown that intercultural contact outside the walls of the classroom can provide a means of expanding intercultural communication and learning from experiential intercultural education. The reported gains of this extracurricular intercultural contact experience can not only complement students' academic studies but also motivate students to improve their English.

Based on the results, a number of suggestions can be put forward to facilitate the development of intercultural competence on the university campus. First, besides encouraging students to participate in SUSIS, more training could be devoted to preparing students in the curriculum of language programs. Students' reports of their experience also suggest the importance of sharing knowledge about one's own culture in intercultural interactions and that more training is needed in academic programs so that 
students can be better equipped to deal with such communicative challenges. Therefore, language teachers can reexamine the cultural content of their classes to see what role information about the local culture, generally taken for granted, can play. Encouraging students to consciously look at their own culture through the eyes of an outsider should be undertaken alongside the discussion of foreign cultures are introduced. Good language teachers help improve students' ability to learn about other cultures as well as providing them new insights on their own culture.

Second, expand and diversify experiential learning opportunities to maximize the potential for intercultural learning. Facilitating international education for home students requires the full support and cooperation of multiple institutions at various levels. This study is one example of how intercultural communication competence beyond EFL classrooms can be facilitated by using international students as language and cultural resources. In the future, the administrators in charge of foreign students may collaborate with language or subject-related teachers and offer mutual support by designing more various intercultural work projects or theme-based activities to enrich and expand the communication topics so that they are not only frequently limited to foods, fairs, or trips by using the campus diversity as valuable resources.

Finally, the outcomes of participation in SUSIS should be shared and widely promoted on campus to draw the interest of even more student in the future. After all, interaction between foreign and local students does not just spontaneously happen. Nor does the existence of cultural diversity in a given institution does automatically lead to harmonious intercultural contact. It needs to be nurtured and guided toward positive outcomes. Similarly, intercultural contact doesn't guarantee intercultural competence.

The results of this study were used as important information to better the intercultural education. It is hoped that curricular design in and outside the classroom constitute a dynamic interplay of teaching and learning processes to shape the lived experience of students and develop the skills, knowledge and attitudes necessary to face a future in an increasingly connected and globalized society.

\section{References}

ALRED, G., \& BYRAM, M. (2002). Becoming an Intercultural Mediator: A Longitudinal Study of Residence Abroad. Journal of Multilingual and Multicultural Education, 23, 339-352. http://dx.doi.org/10.1080/01434630208666473

BENNETT, J. M. (2008). On becoming a global soul. In Developing competence and transformation: Theory, research and application in international education, ed. V. Savicki, 13-31. Sterling: Stylus.

BRAUN, V., \& CLARKE, V. (2006). Using thematic analysis in psychology. Iualitative Research in Psychology, 3(2), 77-101.

BYRAM, M. (1997). Teaching and Assessing Intercultural Communicative Competence. Clevedon: Multilingual Matters

BYRAM, M., \& FENG, A. (2004). Culture and language learning: Teaching, research and scholarship. Language Teaching, 37(10), 149-68.

CHEN, S. Y. (2011). Promoting intercultural understanding and reducing stereotypes. Educational Studies. 37 (1), 73-88

DEARDORFF, D. K. (2011). Assessing intercultural competence. New Directions for Institutional Research, 149. Retrieved from: http://onlinelibrary.wiley.com/doi/10.1002/ir.381/pdf

DEARDORFF, D. K. (2012). Intercultural Competence in the 21st Century: Perspectives, Issues, Application. In Breninger, B., \& Kaltenbacher, T. (Eds.), Creating Cultural Synergies (p. 7-23). Cambridge Scholars.

DEARDORFF, D. K. \& EDWARDS, K. (2012). Research on Intercultural Learning of Students in Service Learning. In Clayton, P. H., Bringle, R.G., \& Hatchers, J. A. (Eds.), Research on Service Learning: Conceptual Frameworks and Assessment (p. 157-186). Sterling, VA: Stylus.

DENZIN, N. K. (1989). The research act, Englewood Cliffs, NJ: Prentice Hall. 
DOLBY, N. (2008). Global citizenship and study abroad: A comparative study of American and Australian undergraduates. Frontiers: The Interdisciplinary Journal of Study Abroad, 17, 51-67. Language acquisition. Canadian Journal of Psychology, 13, 266-272.

FANTINI, A. (2009). Assessing intercultural competence: Issues and tools. In Deardorff, D. K. (Ed.), The SAGE handbook of intercultural competence (p. 456-476).Thousand Oaks, CA: Sage.

GORDON, J., \& DEARDORFF, D. K. (2013). Demystifying assessment: A critical component in student success. In Donohue, D. et al (Eds.), Successful models and best practices for internships, service learning and volunteering abroad (p. 74-81). Washington, DC: NAFSA.

GRADDOL, D. (1999). The decline of the native speaker. AILA Review, (13), 57-68.

GNUTZMANN, C. (2000). Lingua fanca. In Byram, M. (Ed.), The Routledge encyclopedia of language teaching and learning (p. 402-429). London, England: Routledge.

HENDON, V. S. (1980). Introducing culture in the high school foreign language class. Foreign Language Annals, 13(3), 191-199.

HEYWARD, M. (2002). From international to intercultural. Journal of Research in International Education $1(1), 9-32$.

HILLER, G. G. \& WOZNIAK, M. (2009). Developing an intercultural competence programme at an international cross-border university. Intercultural Education 20(4), 113-24.

HUANG, Y., RAYNER, C., \& ZHUANG, L. (2003). Does Intercultural Competence Matter in Intercultural Business Relationship Development? International Journal of Logistics, 6(4), 277-288.

KACHRU, B. B. (1985). Standards, codification and sociolinguistic realism: The English language in the outer circle. In Quirk, R. \& Widdowson, H. (Eds.), English in the world: Teaching and learning the language and literatures (p. 11-30). Cambridge, England: CUP

KACHRU, B. B. (1991). Liberation linguistics and the Quirk concern. English Today, 25, 3-13.

KACHRU, B. B. (1992). Teaching World Englishes. In Kachru, B. B. (Ed.), The other tongue: English cross cultures (p. 355-365). $2^{\text {nd }}$ edition. Urbana, IL. University of Illinois Press.

KACHRU, B. B. (1998). English as an Asia Language. Link \& Letters, 5, 89-108.

KE, I. C. (2011) NNS-NNS online intercultural communication: a sustainable practice to teach global English and develop intercultural communicative competence. Journal of Applied English, 4, 33-45.

KRAMSCH, C. (1998). Language and Culture. Oxford: Oxford University Press.

LEASK, B. (2009). Using formal and informal curricula to improve Interactions between home and international students. Journal of Studies in International Education, 13, 205-221.

Doi:10.1177/1028315308329786

LEE, K. Y. (2012). Teaching intercultural English learning/teaching in World Englishes: Some classroom activities in South Korea. English teaching and: Practice and Critique, 11(4),190-205.

LIU, K. L. (2013). Integrating Home-foreign Students Contact into EFL Classes to Foster Intercultural Competence. Journal of Applied English, 6, 35-49.

LUSTIG, M. W. \& KOESTER, J. (2006). Intercultural competence: Interpersonal communication across cultures. 5th ed. Boston, MA: Pearson.

MERRIAM, S. B. (1998). Qualitative research and case study applications in education. San Francisco: Jossey-Bass.

MIYAMOTO, M. (2012).The Effectiveness of Cross-Cultural Communication-Through Collaborative Activities with International and Japanese Students. Proceedings of 2012 UMAP International Conference, 247-260.

OWEN, W. F.(1984). Interpretive themes in relational communication. Quarterly Journal of Speech, 70, 274-87.

PATTON, M. Q. (1990). Qualitative Evaluation Methods. Thousand Oaks: Sage. Rundstrom, W. T. (2005). Exploring the impact of study abroad on students' intercultural communication skills: Adaptability and sensitivity. Journal of Studies in International Education, 9, 356-371.

SEIDMAN, L. E. (1998). Interviewing as qualitative research. New York: Teachers College Press. 
STUART, D. K. (2009). Assessment instruments for the global workforce. In Moodian, M. (Ed.), Contemporary leadership and intercultural competence: Exploring the cross-cultural dynamics within organizations (p. 175-190). Thousand Oaks, CA: Sage.

SUNG, D. \& CHEN, P. W. (2007). Incorporating culture of English-speaking countries into English education: A case study in Taiwan. English.Edu: Journal of Language Teaching and Research, 7(2), 108-119.

SUNG, D. \& CHEN, P. W. (2009). Incorporating English-language cultures into English learning: Viewpoints from university English faculty in Taiwan. The International Journal of Learning, 16(3), 301-313.

TAYLOR, E. (1994). Intercultural Competency: A Transformative Learning Process. Adult Education Quarterly, 44, 154-174. Available at: http://dx.doi.org/10.1177/074171369404400303 Appendix

VANDE BERG, M., CONNOR-LINTON, J., \& PAIGE, R. M. (2009). The Georgetown Consortium Project: Interventions for student learning abroad. Frontiers: The Interdisciplinary Journal of Study Abroad, $18,1-75$.

WEBER, S. (2005): Intercultural Learning as Identity Negotiation. Frankfurt/M.: Lang.

\section{Contact}

Kai Li LIU

Language Center

Soochow University

70 LinXi Rd, Taipei

Taiwan

liukl@scu.edu.tw 